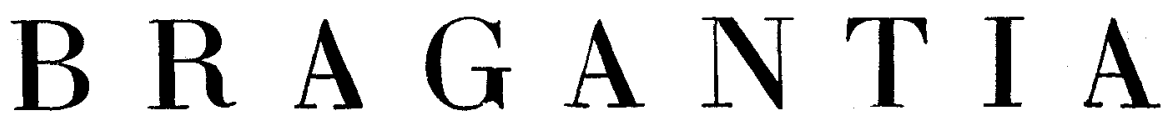

Boletim Científico do Instituto Agronômico do Estado de S. Paulo

Vol. 30

Campinas, outubro de 1971

N. ${ }^{\circ} 14$

\title{
REAÇÃO DE LARANJEIRAS NATAL À APLICAÇÃO DE ADUBOS MINERAIS E ORGÂNICOS NAS COVAS DE PLANTIO (1)
}

LuCiano S. PaEs CRUz, engenheiro-agrônomo, Estação Experimental de Mococa, ODY RODRIGUEZ, engenheiro-agrônomo, Seção, de Citricultura, TosHio IGUE, engenheiro-agrônomo, Seção de Técnica Experimental e Cálculo, Instituto Agronômico

\section{SINOPSE}

Em solo Podzólico Vermelho Amarelo orto, da Estação Experimental de Mococa, foram estudados os efeitos de adubos orgânicos - torta de mamona, estêrco de curral e estêrco de aves - comparados com adubação mineral NP e NPK, todos aplicados em três doses, no desenvolvimento de laranjeiras.

Medições efetuadas nos caules, a $10 \mathrm{~cm}$ acima do ponto de enxertia, no fim de cada estação do ano, revelaram efeitos positivos das adubações minerais com nitrogênio e fósforo, no desenvolvimento das plantas. A inclusão de potássio não provocou efeitos benéficos, sendo até prejudicial, confirmando resultados de trabalhos anteriores. Os adubos orgânicos não diferiram em seus efeitos e apresentaram melhor resultado quando aplicados na dose intermediária. Seu efeito foi, entretanto, inferior ao dos adubos minerais.

O experimento permitiu verificar melhor desenvolvimento em plantas provenientes de mudas que possuiam originalmente $14 \mathrm{~mm}$ de diâmetro no viveiro, em comparação com as que possuiam 12 e $13 \mathrm{~mm}$.

\section{1 - INTRODUÇÃO}

Trabalhos anteriores $(1,2)$ mostraram não haver resposta à adubação com potássio, em viveiros e em laranjeiras novas, nas condições de alguns solos do Estado de São Paulo.

( $\left.{ }^{1}\right)$ Trabalho apresentado na XXI Reuniăo da Sociedade Brasileira para 0 Progresso da Ciência, Pôrto Alegre, 1969. Recebido para publicậão em 18 de maio de 1971 . 
Nesta publicação são apresentados os resultados obtidos em experimento em que se procurou verificar o efeito de $N, P$ e $K$, aplicados nas covas de plantio de laranjeiras Natal (Citrus sinensis, Osbeck), medindo-se as reações das plantas pelo seu desenvolvimento vegetativo até que elas atingissem a primeira produção. Adubos minerais foram comparados com adubos orgânicos, com a finalidade de julgar a reação das laranjeiras a essas duas fontes de nutrientes.

\section{2 - MATERIAL E MÉTODO}

Foram empregados como fertilizantes orgânicos o estêrco de curral, o estêrco de aves e a torta de mamona, e como minerais, o salitre do Chile, o superfosfato simples e o cloreto de potássio. Todos os adubos foram aplicados em três doses, procurando-se €quilibrar o nível de nutrientes das composições minerais com o das composições orgânicas.

O resultado da análise química dos adubos orgânicos empregados, em porcentagem sôbre o pêso sêco, é apresentado na relação seguinte $\left({ }^{2}\right)$ :

$\begin{array}{lccccccc}\text { MATERIAL } & \mathrm{H}_{2} \mathrm{O} & \mathrm{SiO}_{2} & \mathrm{CaO} & \mathrm{MgO} & \mathrm{K}_{2} \mathrm{O} & \mathrm{P}_{2} \mathrm{O}_{5} & \mathrm{~N} \\ \text { stêrco de curral } & 52,7 & 37,2 & 0,7 & 2,1 & 3,5 & 0,9 & 1,8 \\ \text { stêrco de aves } & 33,7 & 21,0 & 6,4 & 1,3 & 2,5 & 4,1 & 2,8 \\ \text { orta de mamona } & 8,7 & 0,5 & 0,9 & 0,8 & 1,1 & 1,8 & 5,4\end{array}$

Foram usadas as seguintes doses de fertilizantes, tomando por base a sua composição em $N$ e $P$, em relação à torta de mamona. Assim, $920 \mathrm{~g}$ de torta de mamona, úmida, com 8,7\% de água, corresponderam a $4000 \mathrm{~g}$ de estêrco de curral com 52,7\% de água; corresponderam também a $1320 \mathrm{~g}$ de estêrco de aves, com $33,7 \%$ de água, e a $300 \mathrm{~g}$ de salitre do Chile + $75 \mathrm{~g}$ de superfosfato simples:

$1-\mathrm{C}_{1}=$ estêrco de curral $4000 \mathrm{~g}$

$2-\mathrm{C}_{2}=$ estêrco de curral $8000 \mathrm{~g}$

$3-\mathbf{C}_{3}=$ estêrco de curral $16000 \mathrm{~g}$

$4-A_{1}=$ estêrco de aves $1320 \mathrm{~g}$

(2) Análise efetuada pela Seção de Pedologia, Instituto Agronômico. 
$5-A_{2}=$ estêrco de aves $2640 \mathrm{~g}$

$6-\mathrm{A}_{3}=$ estêrco de aves $5280 \mathrm{~g}$

$7-\mathrm{M}_{1}=$ torta de mamona $920 \mathrm{~g}$

$8-\mathbf{M}_{2}=$ torta de mamona $1840 \mathrm{~g}$

$9-\mathbf{M}_{3}=$ torta de mamona $3680 \mathrm{~g}$

$10-\mathbf{N}_{1} \mathbf{P}_{1}=$ salitre do Chile $-300 \mathrm{~g}$; superfosfato simples $75 \mathrm{~g}$

$11-\mathrm{N}_{2} \mathrm{P}_{2}=$ salitre do Chile $-600 \mathrm{~g}$; superfosfato simples $150 \mathrm{~g}$

$12-\mathrm{N}_{3} \mathrm{P}_{3}=$ salitre do Chile $-1200 \mathrm{~g}$; superfosfato simples $300 \mathrm{~g}$

$13-\mathrm{N}_{1} \mathrm{P}_{1} \mathrm{~K}_{1}=$ salitre do Chile $-300 \mathrm{~g}$; superfosfato simples - $75 \mathrm{~g}$; cloreto de potássio - $55 \mathrm{~g}$

$14-\mathrm{N}_{2} \mathrm{P}_{2} \mathrm{~K}_{2}=$ salitre do Chile $-600 \mathrm{~g}$; superfosfato simples - $150 \mathrm{~g}$; cloreto de potássio - $110 \mathrm{~g}$

$15-\mathrm{N}_{3} \mathrm{P}_{3} \mathrm{~K}_{3}=$ salitre do Chile $-1200 \mathrm{~g}$; superfosfato simples - $300 \mathrm{~g}$; cloreto de potássio - $220 \mathrm{~g}$

16 - Testemunha $=$ sem adubo.

O experimento foi em parcelas subdivididas, e as parcelas distribuídas em blocos ao acaso, com quatro repetições e três plantas por parcela.

As plantas de laranja Natal (C. sinensis Osb.), clone nucelar, enxertadas em limão Cravo (C. limonia Osb.) provieram de viveiro da Estação Experimental de Limeira. As que foram selecionadas apresentavam diâmetros de 12,13 e $14 \mathrm{~mm}$, a $8 \mathrm{~cm}$ acima do enxêrto. Por não se dispor de plantas de mesmo diâmetro, cada parcela recebeu ao acaso, em 11 de março de 1966, uma planta de cada diâmetro.

O experimento foi instalado na Estação Experimental de Mococa, em gleba de solo Podzólico Vermelho Amarelo orto, segundo a classificação da Comissão de Solos, do Ministério da Agricultura (3). As covas para plantio foram preparadas com um mês de antecedência, aplicando-se os diversos adubos em 
mistura com a terra de enchimento, com exceção do salitre do Chile, que foi aplicado em cobertura, após o plantio. Análises químicas de amostras compostas de solo, tiradas a 0-20 e $20-40 \mathrm{~cm}$ de profundidade, revelaram os seguintes resultados:

$\begin{array}{lcc} & 0-20 \mathrm{~cm} & 20-40 \mathrm{~cm} \\ \mathrm{pH} \ldots \ldots \ldots \ldots \ldots \ldots & 5,55 & 5,65 \\ \text { Carbono } \% \ldots \ldots \ldots \ldots & 1,30 & 0,94 \\ \mathrm{PO}_{4}{ }^{3-}\left(^{3}\right) \ldots \ldots \ldots \ldots \ldots & 0,05 & 0,07 \\ \left.\mathrm{~K}+{ }^{4}\right) \ldots \ldots \ldots \ldots \ldots & 0,35 & 0,48 \\ \mathrm{Ca}^{2}++\mathrm{Mg}^{2}+\left(^{4}\right) \ldots \ldots & 2,60 & 2,20 \\ \left.\mathrm{Al}^{3+}{ }^{4}\right) \ldots \ldots \ldots \ldots \ldots & 0,20 & \text { traços }\end{array}$

Ėsses dados revelam índices satisfatórios de acidez e de $\mathrm{Al}$, nāo exigindo correção para as condições do experimento. O fósforo está em nível de deficiência, e $\mathrm{Ca}+\mathrm{Mg}$, pouco abaixo do nivel inferior médio. $O$ teor de $\mathbf{K}$ é elevado, acima da média.

O clima da região é tropical, com verão chuvoso e inverno sêco. A precipitação pluvial média anual é de 1409,1 milímetros, segundo dados de 28 anos, obtidos no Pôsto Meteorológico da Estação Experimental de Mococa. As temperaturas e as precipitações pluviais médias, ocorridas durante o ensaio, encontram-se no quadro 1.

Após o pegamento das plantas, o ensaio foi conduzido sem irrigação, embora nos meses de junho, julho e agôsto tenha havido precipitações muito baixas ou mesmo falta de chuvas. Os tratos culturais e os tratamentos fitossanitários foram uniformes para tôdas as parcelas. O salitre do Chile foi aplicado em cobertura, $1 / 3$ das doses no primeiro ano e $2 / 3$ no segundo, e diviđiido em três aplicaçōes anuais, ou seja, em janeiro, abril e outubro.

Durante o experimento foram realizadas nove mediçóes do caule das plantas, a $10 \mathrm{~cm}$ acima do ponto de enxertia. Essas mediçōes foram sempre realizadas no fim de cada estação do ano (junho, setembro, dezembro e março).

\footnotetext{
(3) e.mg/100 ml de. solo; teor solúvel em $\mathrm{H}_{2} \mathrm{SO}_{4} 0,05 \mathrm{~N}$.

(4) e.mg/100 $\mathrm{ml}$ de solo; teores trocáveis.
} 
CRUZ, RODRIGUEZ \& IGUE

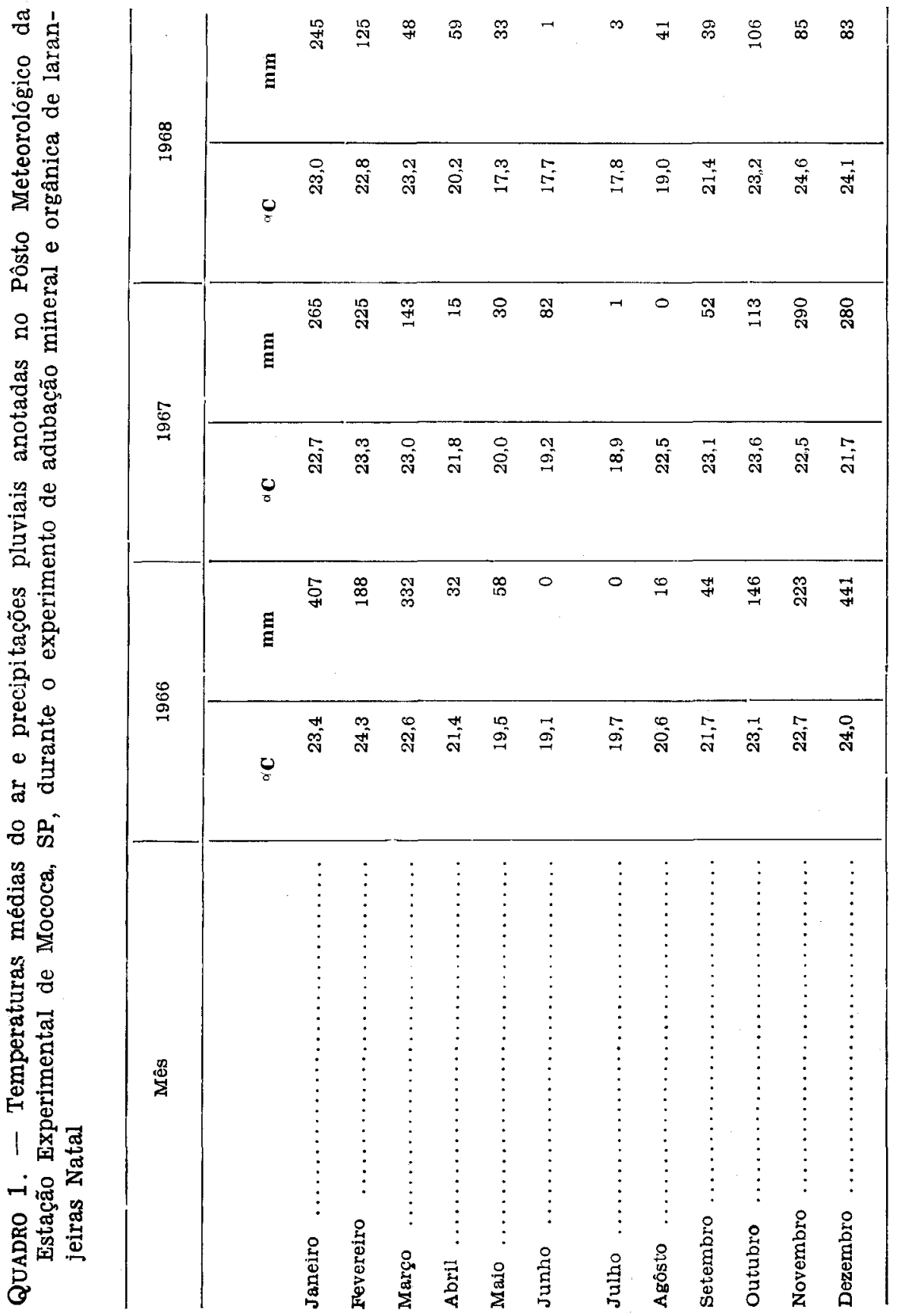




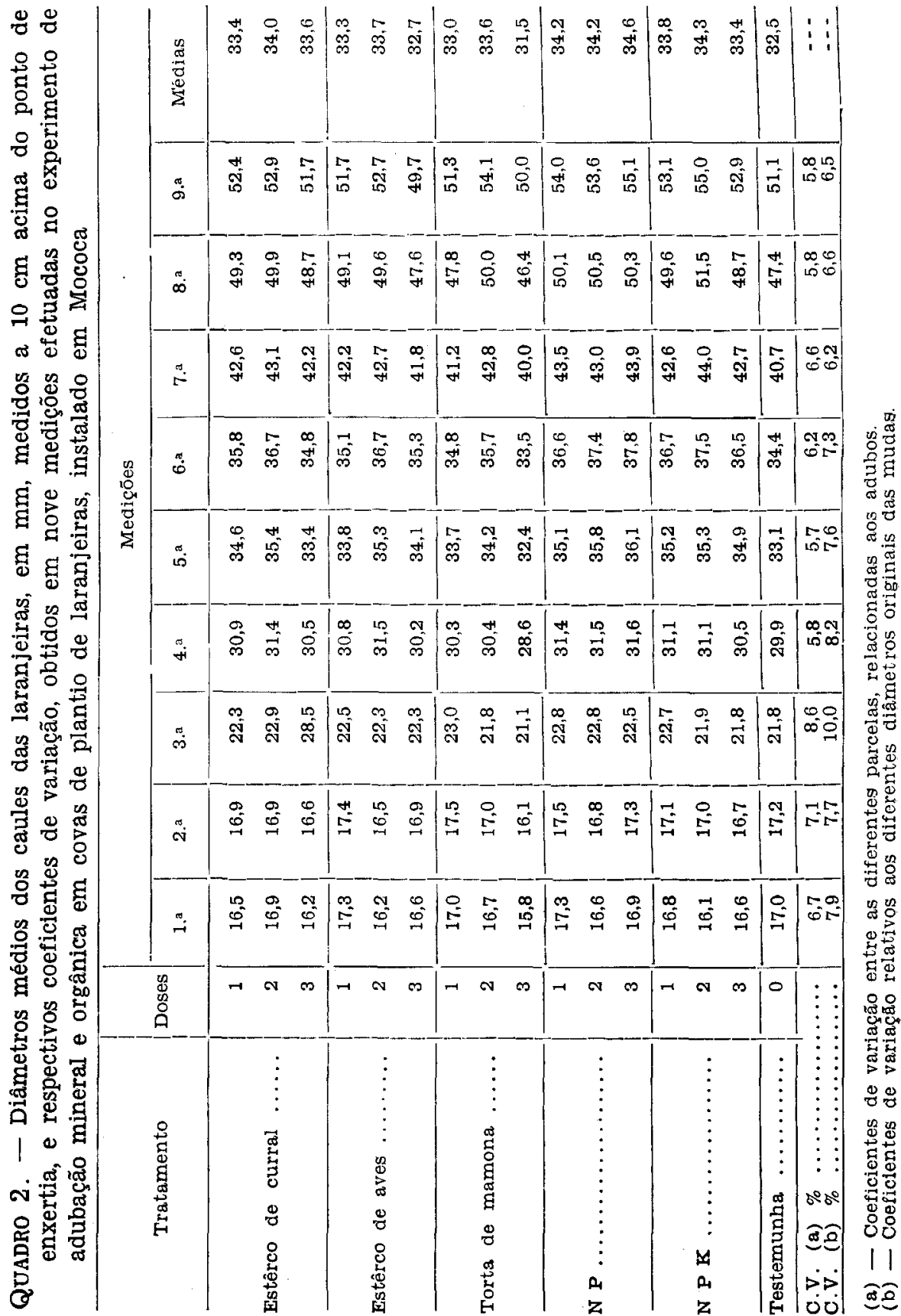




\section{3 - RESULTADOS E DISCUSSÃO}

No quadro 2 são apresentadas as médias das nove medições dos caules das laranjeiras, tomadas a $10 \mathrm{~cm}$ acima do ponto de enxertia, realizadas em junho, setembro e dezembro de 1966; março, junho, setembro e dezembro de 1967; e em março e junho de 1968.

$\mathrm{Na}$ análise da variância dos dados não foram constatadas diferenças significativas entre os diversos adubos orgânicos empregados.

A diferença entre os efeitos provocados pelos adubos orgânicos e minerais foi altamente significativa. A análise estatística revelou que sòmente a partir da quarta mediçāo, um ano após o plantio, tais diferenças foram significativas. O retardamento da reação das plantas aos diferentes tratamentos evidenciou a grande capacidade das citrinas em retirar os nutrientes do solo nos primeiros meses de seu desenvolvimento, desde que o indice de fertilidade seja razoàvelmente bom.

Sòmente a partir da quinta medição a testemunha apresentou-se estatisticamente inferior aos tratamentos adubados.

Segundo o teste de Tukey, os aumentos proporcionados pelos tratamentos NP e NPK, em relação aos adubos orgânicos, foram significativos a $1 \%$ de probabilidade.

Entre as doses, apareceram diferenças estatìsticamente significativas, a partir da quarta medição. Segundo o teste de Tukey, os aumentos proporcionados pela dose 2 dos adubos foram significativos a $5 \%$ de probabilidade. Com exceção do tratamento $N_{3} P_{3}$, em todos os outros a dose maior provocou um retardamento no desenvolvimento d'as plantas. No caso da adubação mineral, tal efeito parece, portanto, ser devido ao excesso de potássio. Êsses dados confirmam resultados obtidos em trabalhos anteriores $(1,2)$, nos quais não se verificaram respostas à aplicação de potássio em viveiros e laranjeiras novas, em alguns solos do Estado de São Paulo.

A proporção de $3: 1 \mathrm{em} N$ e $P$, na adubação mineral, não é definitiva, podendo ser modificada em estudos posteriores.

As médias das medições efetuadas nos diversos tratamentos, tomando em consideração o diâmetro original dos caules das mudas no viveiro, são apresentadas no quadro 3. Desde o plan- 
QUADRo 3. - Diâmetros médios ( $\mathrm{mm}$ ), de caules de laranjeiras Natal, tomados a $10 \mathrm{~cm}$ acima do ponto de enxertia, obtidos no experimento de adubação mineral e orgânica nas covas de plantio, realizado em solo Podzólico Vermelho Amarelo orto, da Estação Experimental de Mococa

\begin{tabular}{|c|c|c|c|c|c|c|c|c|c|}
\hline \multirow{2}{*}{$\begin{array}{l}\text { Diâmetros originais } \\
\text { das plantas no } \\
\text { viveiro (*) }\end{array}$} & \multicolumn{9}{|c|}{ Mediçбes } \\
\hline & $1 . \mathrm{a}$ & $2 . a$ & 3.3 & $4 . \mathrm{a}$ & $5 . \mathrm{a}$ & $6 . \mathrm{a}$ & 7.a & 8. ${ }^{\mathrm{a}}$ & 9.a \\
\hline D $12 \ldots \ldots \ldots \ldots$ & 15,5 & 15,7 & 21,5 & 29,7 & 33,8 & 35,8 & 41,4 & 48,4 & 51,5 \\
\hline D $13 \ldots \ldots \ldots \ldots \ldots$ & 16,5 & 16,8 & 22,2 & 31,0 & 34,8 & 36,2 & 42,8 & 49,4 & 53,0 \\
\hline$D 14 \ldots$ & 17,9 & 18,3 & 23,3 & 31,4 & 35,0 & 36,4 & 43,1 & 49,6 & 53,3 \\
\hline
\end{tabular}

(*) Tomados a $8 \mathrm{~cm}$ acima do ponto de enxertia.

tio das mudas até a última medição (junho de 1968), as plantas que sairam do viveiro com $14 \mathrm{~mm}$, tomadas em conjunto, mantiveram-se mais desenvolvidas do que as que o deixaram com 12 e $13 \mathrm{~mm}$. Embora o assunto não se enquadre na essência do trabalho proposto, ficou evidenciada a necessidade de ser considerado o vigor das plantas em ensaios desta ordem.

Os coeficientes de variação foram baixos em tôdas as medições, conforme é apresentado no quadro 2.

\section{4 - CONCLUSÕES}

As seguintes conclusões gerais podem ser tiradas do presente experimento:

1 - Considerando os dois grupos de adubos, minerais e orgânicos, os primeiros provocaram melhor desenvolvimento das plantas.

2 - Não houve diferença significativa entre os adubos orgânicos, com respeito ao crescimento das laranjeiras. 
3 - Os melhores efeitos no crescimento dias plantas foram obtidos com as adubações minerais que continham nitrogênio e fósforo. A inclusão de potássio provocou efeito depressivo, principalmente na maior dosagem.

4 - Os resultados do presente ensaio sugerem a continuação dos estudos para definição das melhores proporções e quantidades de $\mathrm{N}$ e $\mathrm{P}$, bem como outros estudos correlatos.

\section{GROWTH RESPONSE TO FERTILIZERS ON NATAL SWEET ORANGE} TREES

\section{SUMMARY}

The effects of three levels of organic and inorganic fertilizers on stalk growth of orange trees were evaluated in Red-Yellow Podzolic soil.

It was considered the effects of cattle manure, chicken manure, castor bean bran, as well as Chilean nitrate, ordinary superphosphate and muriate of potash on culm diameter. Measurements made $10 \mathrm{~cm}$ above the graft point indicated positive effect of nitrogen and phosphorus on increasing stalk diameter. Potash did not contribute to development but yielded negative effect confirming precedent results.

The organic fertilizers did not differ among themselves and had less effect than the mineral sources. The organic fertilizers gave better response when intermediate dosages were applied.

\section{LITERATURA CITADA}

1. RODRIGUEZ, O.; ROESSING, C. \& ABRAMIDES, E. Reação de plantas citricas em viveiro à adubação $\mathrm{N}, \mathrm{P}$ e $\mathrm{K}$. Ciência e Cultura 17:201, 1965.

2. — MOREIRA, S. Citrus nutrition - 20 years of experimental results in the State of São Paulo, Brazil. In: Chapman, H. D., ed. International Citrus Symposium, lst, Riverside, 1968. Proceedings. Riverside, University of California, 1969. v.3, p.1579-1586.

3. SERVIÇO NACIONAL DE PESQUISAS AGRONÓMICAS. COMISSÃO DE SOLOS. Levantamento de reconhecimento dos solos do Estado de São Paulo. Rio de Janeiro, Ministério da Agricultura, 1960. 634p. (Boletim 12)

4. SMITH, P. F. Citrus nutrition. In: Childers, N. F. ed. Nutrition of fruit crops: tropical, sub-tropical, temperate trees and small fruits. New Brunswick, Rutgers State University, 1966. p.174207. 